\title{
High-Speed (Subsecond) Measurement of Heat Capacity, Electrical Resistivity, and Thermal Radiation Properties of Tungsten in the Range 2000 to $3600 K^{*}$
}

\author{
A. Cezairliyan and J. L. McClure \\ Institute for Materials Research, National Bureau of Standards, Washington, D.C. 20234
}

(April 14, 1971)

\begin{abstract}
Measurements of heat capacity, electrical resistivity, hemispherical total emittance, and normal spectral emittance of tungsten above $2000 \mathrm{~K}$ by a pulse heating technique are described. Duration of an individual experiment, in which the specimen is heated from room temperature to near its melting point, is less than one second. Temperature measurements are made with a photoelectric pyrometer. Experimental quantities are recorded with a digital data acquisition system, which has a full-scale signal resolution of one part in 8000 . Time resolution of the entire system is $0.4 \mathrm{~ms}$. Results on the above properties of tungsten in the range 2000 to $3600 \mathrm{~K}$ are reported and are compared with those in the literature. Estimated inaccuracy of measured properties in the above temperature range is: 2 to 3 percent for heat capacity, 1 percent for electrical resistivity, 3 percent for hemispherical total and normal spectral emittances.
\end{abstract}

Key words: Electrical resistivity; emittance; heat capacity; high-speed measurements; high temperature; thermal radiation properties; thermodynamics; tungsten.

\section{Introduction}

Tungsten has the highest melting point (above $3600 \mathrm{~K})$ of any known metal. Because of the difficulties involved in performing accurate experiments by conventional techniques at temperatures above approximately $2500 \mathrm{~K}$, a high-speed method was developed to measure heat capacity, electrical resistivity, hemispherical total emittance and normal spectral emittance of electrical conductors. In this paper, application of this technique to measurements on tungsten in the temperature range 2000 to $3600 \mathrm{~K}$ is described.

The method is based on rapid resistive self-heating of the specimen from room temperature to near its melting point. During the short experiment, which lasts less than $1 \mathrm{~s}$, current flowing through the specimen, potential across the specimen and specimen temperature are measured. Temperature measurements are made with a high-speed photoelectric pyrometer [1]. ${ }^{1}$ Recordings of experimental quantities are made with a digital data acquisition system, which has a time resolution of $0.4 \mathrm{~ms}$, and a full-scale signal resolution of one part in 8000 . Details regarding the construction and operation of the measurement system, and other pertinent information, such as formulation

*This work was supported in part by the Directorate of Aeromechanics and Energetics, U.S. Air Force Office of Scientific Research under contract ISSA-70-0002.

${ }^{1}$ Figures in brackets indicate the literature references at the end of this paper. of relations for properties etc., are given in earlier publications $[2,3]$ in connection with measurements on molybdenum and tantalum.

\section{Measurements}

The measurements were made in the temperature interval 1900 to $3600 \mathrm{~K}$. To optimize the operation of the pyrometer, this temperature interval was divided into four ranges: low, 1900 to $2200 \mathrm{~K}$; medium, 2150 to $2500 \mathrm{~K}$; high, 2450 to $2900 \mathrm{~K}$; and very high, 2850 to $3600 \mathrm{~K}$. Two experiments were conducted in each range; and three additional experiments were conducted in the first three ranges in which the surface radiance of the specimen was measured. Before the start of the experiments, the specimen was annealed by subjecting it to approximately 30 heating pulses (up to $3200 \mathrm{~K}$ ).

The duration of the current pulses in the experiments ranged from 410 to $630 \mathrm{~ms}$ depending on the desired final temperature. The average heating rate of the specimen was: $7100 \mathrm{~K} \mathrm{~s}^{-1}$ at $2000 \mathrm{~K}, 5600 \mathrm{~K} \mathrm{~s}^{-1}$ at $3000 \mathrm{~K}$, and $3700 \mathrm{~K} \mathrm{~s}^{-1}$ at $3600 \mathrm{~K}$. At these temperatures, radiative heat losses from the specimen amounted to approximately 3,12 , and 27 percent of the input power, respectively. All of the experiments were conducted with the specimen in a vacuum environment of approximately $10^{-4}$ torr.

The data on voltage, current, and temperature were used to obtain third degree polynomial functions for 

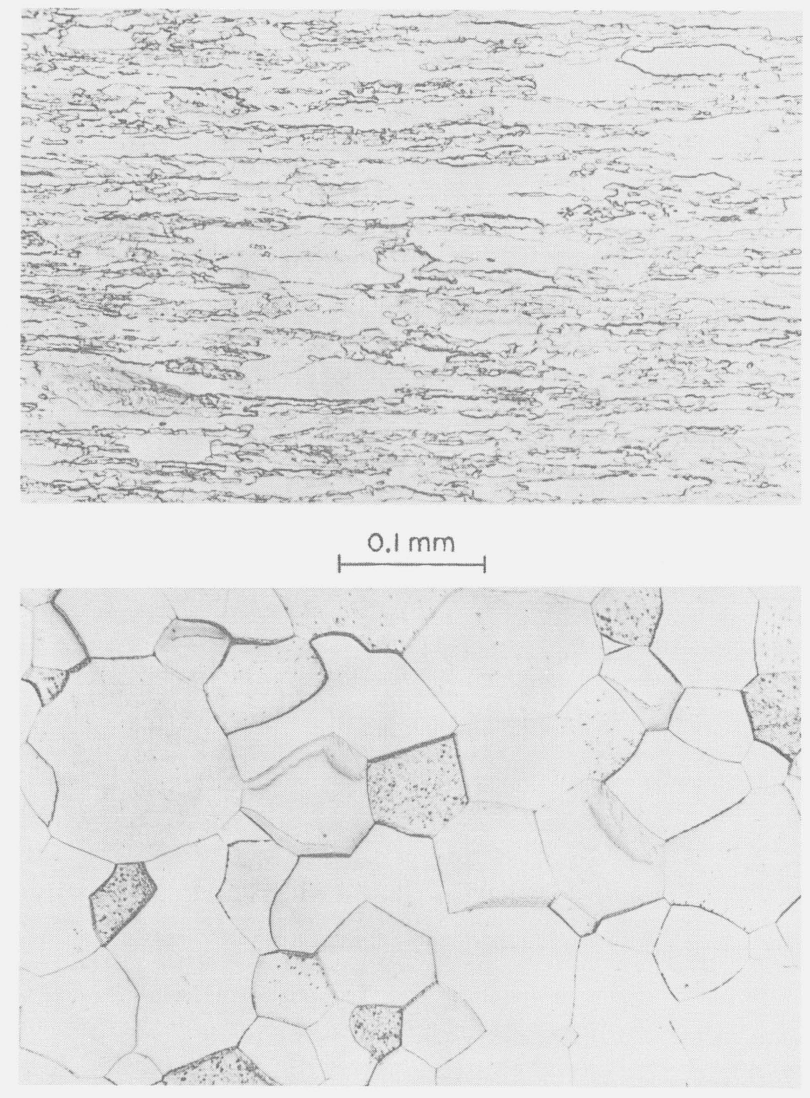

FigURE 1. Photomicrographs of the tungsten specimen before (upper photograph) and after (lower photograph) the entire set of experiments.

each quantity in terms of time, which then provided the input information for the determination of properties.

The pyrometer was calibrated before and after the entire set of experiments against a tungsten-filament standard lamp, which in turn was calibrated against the NBS temperature standard. The digital recording system, including the differential amplifiers, was also calibrated before and after the entire set of experiments. The details of the calibration procedures are given in an earlier publication [2].

The specimen was a tube fabricated from a tungsten rod by removing the center portion by an electroerosion technique. The outer surface of the specimen was polished to reduce heat loss due to thermal radiation. The nominal dimensions of the specimen were: length, 4 in $(101 \mathrm{~mm})$; outside diameter, 0.25 in $(6.3$ $\mathrm{mm})$; and wall thickness, 0.02 in $(0.5 \mathrm{~mm})$.

Specimen characterization was made by the following methods: photomicrography, spectrochemical analysis, and residual resistivity ratio. Photomicrographs of the specimen (figure 1) indicate that considerable grain growth took place as the result of pulse heating to high temperatures. A list of the nature and composition of impurities in the specimen, at the end of the entire set of experiments as determined by
TABLE 1. Impurities in tungsten specimen

\begin{tabular}{l|c}
\hline \hline Impurity & $\begin{array}{c}\text { Composition, ppm } \\
\text { (by weight) }\end{array}$ \\
\hline $\mathrm{Al}$ & 5 \\
$\mathrm{~B}$ & $<2$ \\
$\mathrm{Ca}$ & 15 \\
$\mathrm{Cr}$ & 5 \\
$\mathrm{Co}$ & $<2$ \\
$\mathrm{Cu}$ & 10 \\
$\mathrm{Fe}$ & 60 \\
$\mathrm{Mg}$ & $<2$ \\
$\mathrm{Mn}$ & $<2$ \\
$\mathrm{Mo}$ & 310 \\
$\mathrm{Nb}$ & $<20$ \\
$\mathrm{Ni}$ & $<2$ \\
$\mathrm{~Pb}$ & $<2$ \\
$\mathrm{Si}$ & 5 \\
$\mathrm{Sn}$ & $<2$ \\
$\mathrm{Sr}$ & $<2$ \\
$\mathrm{Th}$ & $<250$ \\
$\mathrm{Ti}$ & 10 \\
$\mathrm{Zr}$ & 30 \\
\hline \multicolumn{2}{c}{$450<$ Total $<740$}
\end{tabular}

spectrochemical analysis, ${ }^{2}$ is given in table 1 . The residual resistivity ratio of the specimen (ratio of electrical resistivity at $273 \mathrm{~K}$ to that at $4 \mathrm{~K}$ ), measured before the experiments, was 41 .

The "effective" mass of the specimen was calculated from the total mass by the ratio of the geometric surface area between voltage probes to total surface area. Length measurements at room temperature were made with a micrometer microscope. The cross-sectional area of the specimen was calculated from the mass, density, and geometry. Density of the tungsten specimen was measured at $293 \mathrm{~K}$ to be $19.23 \times 10^{3} \mathrm{~kg} \mathrm{~m}^{-3}$. This compares favorably with a previously cited value of $19.3 \times 10^{3} \mathrm{~kg} \mathrm{~m}^{-3}$ [4].

\section{Experimental Results}

This section presents the thermophysical properties determined from the measured quantities. All values are based on the 1968 International Practical Temperature Scale [5]. In all computations, the geometrical quantities are based on their room temperature (298 K) dimensions. The experimental results are represented by polynomial functions in temperature obtained by least squares approximation of the individual points. The final values on properties at 100 degree temperature intervals computed using the functions are presented in table 2. Results obtained from individual experiments, by the method described previously [2], are given in the appendix (tables A-1, $\mathrm{A}-2$, and $\mathrm{A}-3$ ). The patterns of deviations of individual data points from the smooth functions for the properties are similar to those in the earlier work on tantalum [3].

\footnotetext{
${ }^{2}$ Spectrochemical analysis of the tungsten specimen was made by the Lamp Metals and Components Department of the General Electric Company.
} 
TABLE 2. Heat capacity, electrical resistivity, hemispherical total emittance and normal spectral emittance of tungsten

\begin{tabular}{c|c|c|c|c}
\hline \hline Temp. & $\begin{array}{c}c_{p} \\
K\end{array}$ & $\begin{array}{c}\rho^{\mathrm{a}} \\
m o l^{-1}\end{array} K^{-1}$ & $\epsilon^{-8} \Omega m$ & \\
\hline & & & & \\
2000 & 31.65 & 56.22 & ${ }^{\mathrm{b}} 0.318$ & 0.379 \\
2100 & 32.49 & 59.74 & .321 & .379 \\
2200 & 33.29 & 63.25 & ${ }^{\mathrm{b}} .324$ & .379 \\
2300 & 34.08 & 66.77 & .326 & .379 \\
2400 & 34.89 & 70.28 & .329 & .379 \\
2500 & 35.72 & 73.80 & .332 & .379 \\
2600 & 36.61 & 77.31 & .335 & .379 \\
2700 & 37.57 & 80.83 & .338 & .379 \\
2800 & 38.63 & 84.34 & .340 & .379 \\
2900 & 39.81 & 87.86 & .343 & .379 \\
3000 & 41.14 & 91.37 & .346 & .379 \\
3100 & 42.62 & 94.89 & .349 & \\
3200 & 44.29 & 98.40 & .351 & \\
3300 & 46.17 & 101.92 & .354 & \\
3400 & 48.27 & 105.43 & .357 & \\
3500 & 50.63 & 108.95 & & \\
3600 & 53.25 & 112.46 & & \\
\hline
\end{tabular}

"Based on ambient-temperature (298 K) dimensions.

b Extrapolated from higher temperature results.

\subsection{Heat Capacity}

Heat capacity was computed from data taken during the heating period. A correction for power loss due to thermal radiation was made using the results on hemispherical total emittance. The function for heat capacity (standard deviation $=0.7 \%$ ) that represents the results in the temperature range 2000 to $3600 \mathrm{~K}$ is:

$c_{p}=-25.71+6.331 \times 10^{-2} T-2.459 \times 10^{-5} T^{2}$

$$
+3.638 \times 10^{-9} T^{3}
$$

where $T$ is in $\mathrm{K}$ and $c_{p}$ in $\mathrm{J} \mathrm{mol}^{-1} \mathrm{~K}^{-1}$. In the computations of the heat capacity, the atomic weight of tungsten was taken as 183.85 .

To determine the effect of thermal cycling on heat capacity, the results of four additional experiments covering the range 2000 to $3300 \mathrm{~K}$ were compared with those reported above. The average absolute difference between the two sets of results was less than 0.1 percent, which is smaller than the measurement resolution. This indicates that the measurements were not sensitive to thermal cycling.

\subsection{Electrical Resistivity}

The electrical resistivity of tungsten was determined from the same experiments that were used to calculate the heat capacity. The function for electrical resistivity (standard deviation $=0.4 \%$ ) that represents the results in the temperature range 2000 to $3600 \mathrm{~K}$ is:

$$
\rho=-14.08+3.515 \times 10^{-2} T
$$

where $T$ is in $\mathrm{K}$ and $\rho$ in $10^{-8} \Omega \mathrm{m}$. The results of thermal cycling indicate an average absolute difference of less than 0.5 percent in electrical resistivity. The measurement, before the pulse experiments, of the electrical resistivity of the specimen at $293 \mathrm{~K}$ with a Kelvin bridge yielded a value of $5.45 \times 10^{-8} \Omega \mathrm{m}$.

\subsection{Hemispherical Total Emittance}

Hemispherical total emittance was computed using data taken during both heating and initial free cooling periods. The function for hemispherical total emittance (standard deviation $=1 \%$ ) that represents the results in the temperature range 2300 to $3400 \mathrm{~K}$ is:

$$
\epsilon=0.2627+2.770 \times 10^{-5} \mathrm{~T}
$$

where $T$ is in $\mathrm{K}$.

\subsection{Normal Spectral Emittance}

Normal spectral emittance was computed using data from three sets of two experiments, one in which the pyrometer was aimed at the surface of the specimen, and another in which it was aimed at the blackbody hole in the specimen. The target on the surface was a narrow flat surface ground along the specimen. The measurements were made at the effective wavelength of the pyrometer interference filter $(650 \mathrm{~nm}$; bandwidth $10 \mathrm{~nm}$ ). The function for normal spectral emittance (standard deviation $=0.2 \%$ ) that represents the results in the temperature range 2000 to $3000 \mathrm{~K}$ is:

$$
\epsilon_{N, \lambda}=0.3804-5.060 \times 10^{-7} T
$$

where $T$ is in $\mathrm{K}$.

\section{Estimate of Errors}

Estimates of errors in measured and computed quantities lead to the following estimates of errors in the properties over the temperature range 2000 to $3600 \mathrm{~K}$.

Heat capacity: 2 percent at $2000 \mathrm{~K}, 3$ percent at $3600 \mathrm{~K}$.

Electrical resistivity: 1 percent

Hemispherical total emittance: 3 percent

Normal spectral emittance: 3 percent

Details regarding the estimates of errors and their combination in high-speed experiments using the present measurement system are given in a previous publication [2]. Specific items in the error analysis were recomputed whenever the present conditions differed from those in the earlier publication.

\section{Discussion}

The heat capacity and electrical resistivity results of this work are compared graphically with those in the literature in figures 2 and 3 , respectively. Numerical comparisons are given in tables 3 and 4 . It may be 

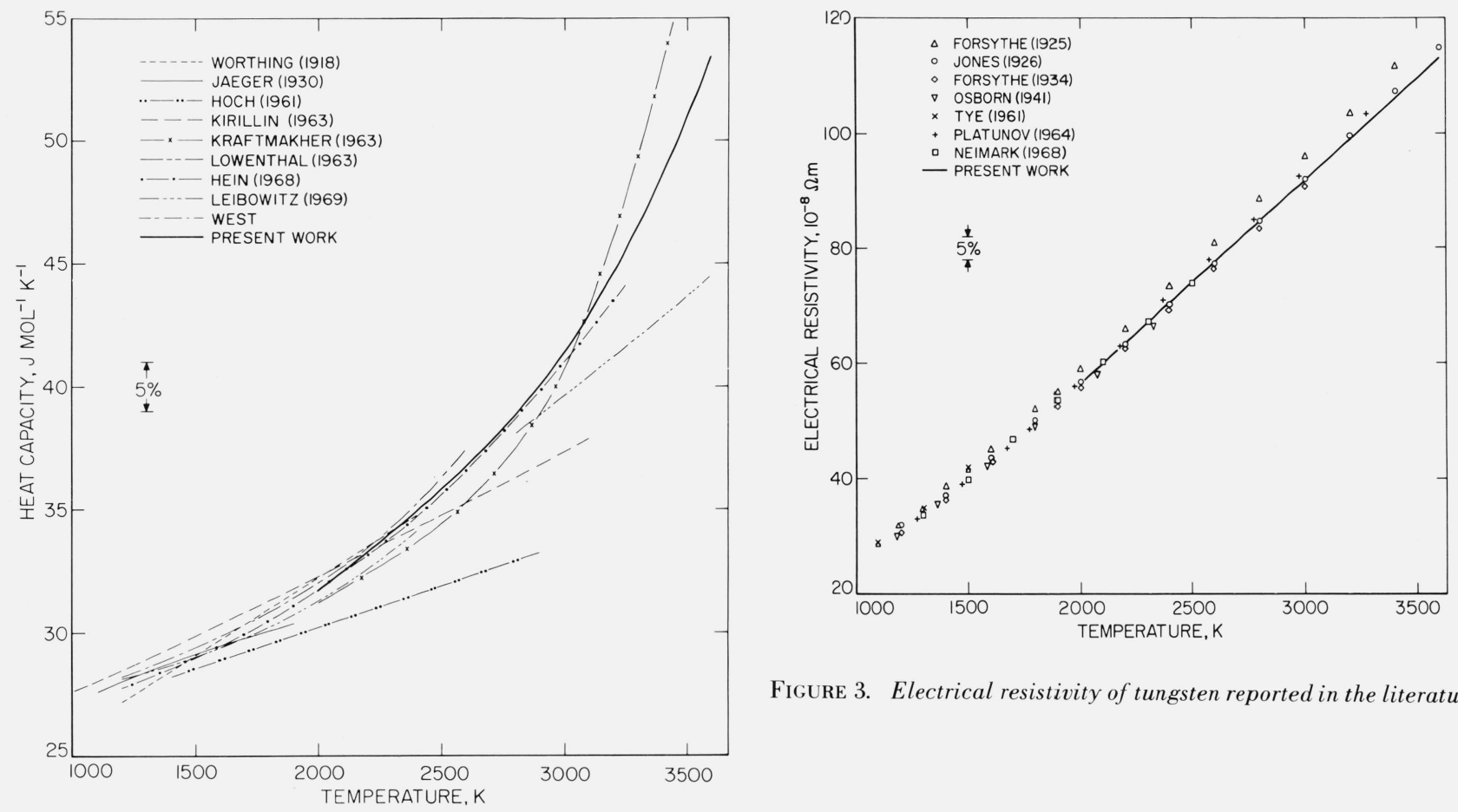

FIGURE 3. Electrical resistivity of tungsten reported in the literature.

FIGURE 2. Heat capacity of tungsten reported in the literature.

TABLE 3. Tungsten heat capacity difference (previous literature values minus present work values) in percent

\begin{tabular}{|c|c|c|c|c|c|c|c|c|c|c|c|c|}
\hline \multirow{2}{*}{ Investigator } & \multirow{2}{*}{ Ref. } & \multirow{2}{*}{ Year } & \multirow{2}{*}{ Method } & \multicolumn{9}{|c|}{ Temperature, $\mathrm{K}$} \\
\hline & & & & 2000 & 2200 & 2400 & 2600 & 2800 & 3000 & 3200 & 3400 & 3600 \\
\hline 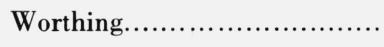 & 10 & 1918 & pulse & +1.6 & +0.3 & -0.7 & & & & & & \\
\hline Jaeger and Rosenbohm........... & 11 & 1930 & drop & $\mathrm{a}-3.2$ & & & & & & & & \\
\hline Hoch and Johnston............... & 12 & 1961 & drop & -4.7 & -7.3 & -9.7 & -12 & -15 & & & & \\
\hline Kirillin et al.................... & 13 & 1963 & drop & +1.6 & -0.4 & -2.1 & -4.0 & -6.7 & -9.7 & & & \\
\hline Kraftmakher and Strelkov...... & 14 & 1963 & modul. & -1.4 & -2.4 & -3.6 & -4.0 & -3.2 & -0.8 & +3.4 & +9.5 & +17 \\
\hline Lowenthal....................... & 15 & 1963 & modul. & -1.5 & -2.3 & -2.4 & & & & & & \\
\hline Hein and Flagella.................. & 16 & 1968 & drop & -.03 & -0.7 & -0.6 & -0.2 & -0.1 & -0.7 & -2.4 & & \\
\hline Leibowitz et al......... & 17 & 1968 & drop & & & & & -1.8 & -4.1 & -7.5 & -12 & -17 \\
\hline West and Ishihara................... & 18 & & drop & +1.0 & +0.4 & +0.8 & +1.9 & & & & & \\
\hline
\end{tabular}

a Extrapolated from $1873 \mathrm{~K}$.

seen that most of the results are in general agreement at $2000 \mathrm{~K}$. Considerable disagreement in heat capacity exists above $2500 \mathrm{~K}$. This may be expected, since above this temperature accuracy of heat capacity measured by conventional methods decreases rapidly. Estimates of errors in papers cited lead to an estimate of in- accuracies in previously reported heat capacity and electrical resistivity of approximately 5 to 15 and 1 to 5 percent, respectively, in the temperature range considered. The present result of the electrical resistivity of tungsten corresponding to $293 \mathrm{~K}$, as well as values reported in the literature, are given in table 5. 
TABLE 4. Tungsten electrical resistivity difference (previous literature values minus present work) in percent

\begin{tabular}{|c|c|c|c|c|c|c|c|c|c|c|c|}
\hline \multirow{2}{*}{ Investigator } & \multirow{2}{*}{ Ref. } & \multirow{2}{*}{ Year } & \multicolumn{9}{|c|}{ Temperature, $\mathrm{K}$} \\
\hline & & & 2000 & 2200 & 2400 & 2600 & 2800 & 3000 & 3200 & 3400 & 3600 \\
\hline Forsythe and Worthing....... & 19 & 1925 & +5.1 & +4.7 & +4.6 & +4.8 & +4.9 & +5.2 & +5.5 & +5.9 & \\
\hline Jones.. & 20 & 1926 & +0.8 & +0.2 & +0.1 & +0.1 & +0.4 & +0.7 & +1.2 & +1.7 & +2.2 \\
\hline Forsythe and Watson.. & 32 & 1934 & -0.9 & -1.3 & -1.5 & -1.4 & -1.3 & -1.1 & & & \\
\hline Osborn.......... & 21 & 1941 & -0.4 & -0.6 & & & & & & & \\
\hline Platunov and Fedorov...... & 22 & 1964 & +1.1 & +1.2 & +1.9 & +2.2 & +2.4 & +2.5 & +2.5 & & \\
\hline Neimark and Voronin... & 23 & 1967 & +1.2 & +0.7 & +0.5 & & & & & & \\
\hline
\end{tabular}

TABLE 5. Electrical resistivity of tungsten at $293 \mathrm{~K}$

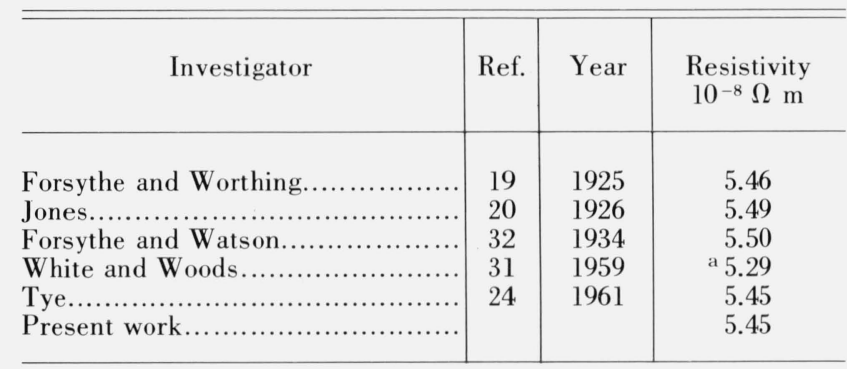

adeal resistivity.

The results for hemispherical total emittance and normal spectral emittance of this work and those in the literature are presented in figures 4 and 5 , respectively. Because of the strong dependence of emittance on surface conditions, considerable deviations exist in the results of various investigators.

Heat capacity results at high temperatures are considerably higher than the Dulong and Petit value of $3 R$. Some of this departure is due to $c_{p}-c_{v}$ and the electronic terms. However, they do not account for the entire departure. Heat capacity above the Debye temperature may be expressed by

$$
c_{p}=A-\frac{B}{T^{2}}+C T+\Delta c
$$

where the constant term is $3 R\left(24.943 \mathrm{~J} \mathrm{~mol}^{-1} \mathrm{~K}^{-1}\right)$, the term in $T^{-2}$ is the first term in the expansion of the Debye function, the term in $T$ represents $c_{p}-c_{v}$ and electronic contributions, and the quantity $\Delta c$ represents excess in measured heat capacity at high temperatures, which is not accounted for by the first three terms. The coefficients $B\left(7.72 \times 10^{4}\right)$ and $C(2.33$ $\times 10^{-3}$ ) were obtained from data on heat capacity at room and moderate temperatures (at 298.15 and $1000 \mathrm{~K})$ given by Hultgren et al. [6].

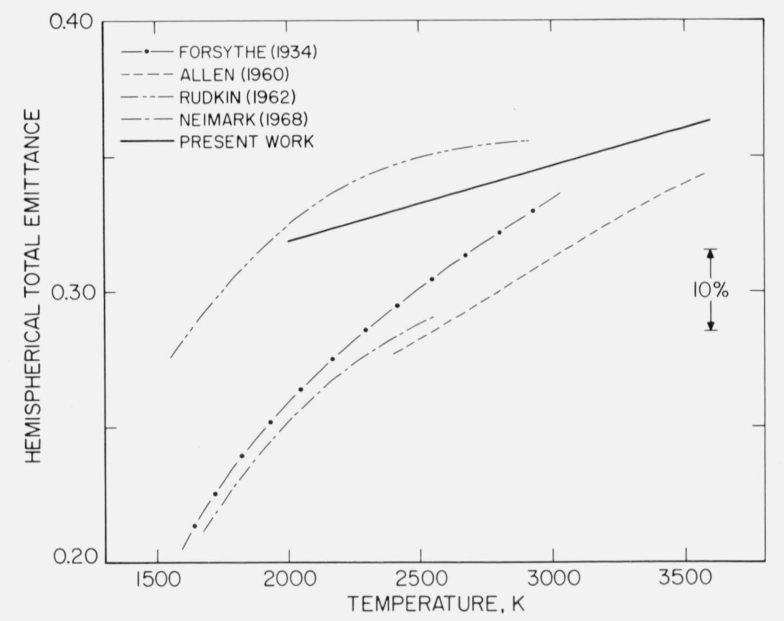

FIGURE 4. Hemispherical total emittance of tungsten reported in the literature.

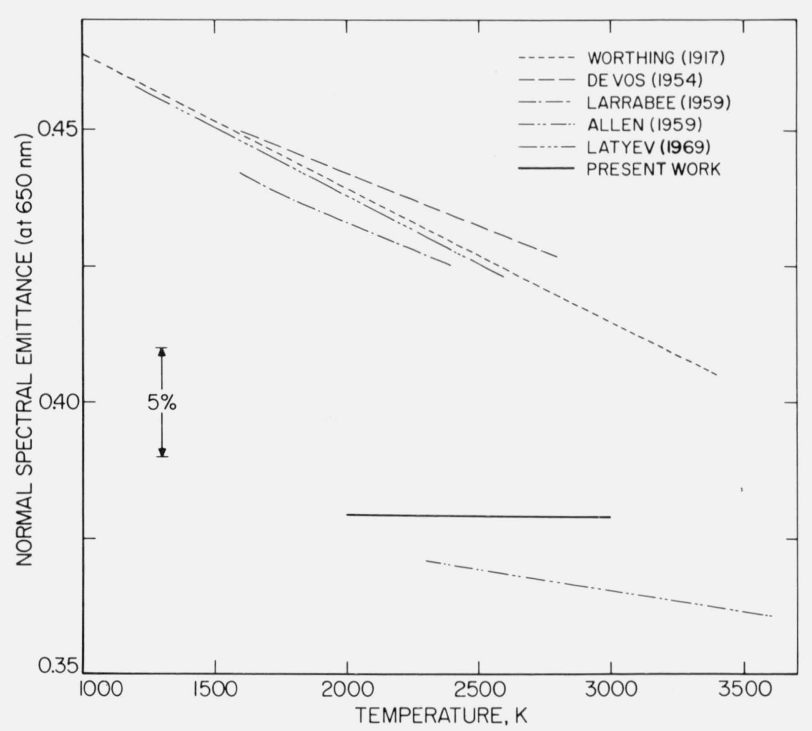

Figure 5. Normal spectral emittance of tungsten at $\lambda=650 \mathrm{~nm}$ reported in the literature. 
TABLE 6. Excess heat capacity $\Delta \mathrm{c}$ in eq (5) and estimated vacancy contribution to heat capacity of tungsten

\begin{tabular}{c|c|c}
\hline \hline $\mathrm{T}$ & $\Delta c$ & $\begin{array}{c}c_{\mathrm{vac}} \\
K\end{array}$ \\
$J \mathrm{~mol}^{-1} K^{-1}$ & $J \mathrm{~mol}^{-1} K^{-1}$ \\
\hline 2000 & 2.07 & 0.0005 \\
2200 & 3.24 & .002 \\
2400 & 4.37 & .009 \\
2600 & 5.62 & .03 \\
2800 & 7.18 & .06 \\
3000 & 9.21 & .14 \\
3200 & 11.90 & .26 \\
3400 & 15.41 & .47 \\
3600 & 19.93 & .79 \\
\hline
\end{tabular}

Using eq (5) and the heat capacity results of this work, the quantity $\Delta c$ was computed for temperatures above $2000 \mathrm{~K}$. The results are tabulated ir table 6 . The uncertainty in the computed $\Delta c$ may be as high as $1 \mathrm{~J} \mathrm{~mol}^{-1} \mathrm{~K}^{-1}$. This was obtained from the combined uncertainties in the coefficients in eq (5) and the measured heat capacities.

Although the mechanisms of vacancy generation become important at high temperatures, it was not possible to attribute the high values entirely to vacancies. To demonstrate this, a crude estimate of the contribution of vacancies to heat capacity was made using the method described in a previous publication [2]. The reported values for vacancy formation energy of tungsten are $3.3 \mathrm{eV}$ [7] and $3.6 \mathrm{eV}$ [8]. Results of quenching experiments on various refractory elements $[7,9]$ have indicated that vacancy concentrations are probably in the range 0.01 to 0.1 percent at their melting points. Estimates corresponding to a vacancy concentration of 0.1 percent at the melting point and a vacancy formation energy of $3.3 \mathrm{eV}$ are given in table 6 . The results indicate that vacancy contribution would be small, less than $0.8 \mathrm{~J} \mathrm{~mol}^{-1} \mathrm{~K}^{-1}$ (upper limit) at $3600 \mathrm{~K}$, and would not account for the high heat capacity values.

If the entire difference between measured and computed [using the first three terms in eq (5)] heat capacities is attributed to vacancies, values of $1.3 \mathrm{eV}$ for energy and 12 percent for concentration at the melting point are obtained. Both of these values seem to be unrealistic for tungsten.

To give a simple expression for the heat capacity of tungsten over a wide temperature range, an empirical

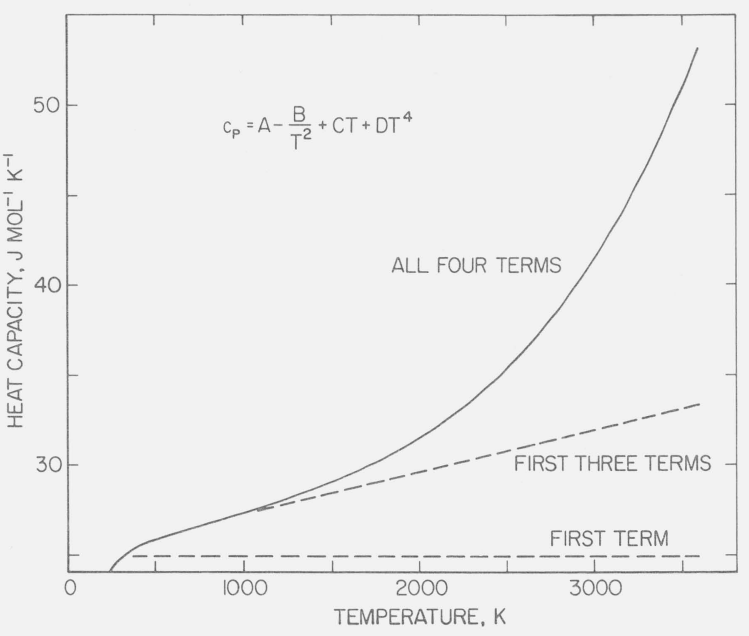

Figure 6. Heat capacity of tungsten according to eq (6).

term in $T^{4}$ for the quantity $\Delta c$ in eq (5) was substituted. The coefficient of this term was obtained from the results of the present work in conjunction with the valiues given by Hultgren et al. [6] at temperatures below $1000 \mathrm{~K}$. Then, eq (5) for the range 300 to $3600 \mathrm{~K}$ becomes

$$
\begin{aligned}
c_{p}=24.943-\frac{7.72 \times 10^{4}}{T^{2}}+ & 2.33 \times 10^{-3} T \\
& +1.18 \times 10^{-13} T^{4}
\end{aligned}
$$

where $T$ is in $\mathrm{K}$ and $c_{p}$ in $\mathrm{J} \mathrm{mol}^{-1} \mathrm{~K}^{-1}$. Average absolute deviation of the individual points from the function over the temperature range considered is 0.2 percent. Equation (6) is presented graphically in figure 6.

The experimental results reported in this paper have further substantiated the feasibility of accurate simultaneous measurement of selected properties above $2000 \mathrm{~K}$ by a millisecond resolution pulse method.

The authors express their gratitude to C. W. Beckett for his interest and encouragement of research in high-speed methods of measuring thermophysical properties. They also extend their appreciation to M. S. Morse for his contribution in connection with electronic instrumentation, which is a vital part of the entire measurement system. 


\section{Appendix}

TABLE A-1. Experimental results on heat capacity and electrical resistivity of tungsten ${ }^{\text {a }}$

\begin{tabular}{|c|c|c|c|c|c|}
\hline \multirow{2}{*}{ Range } & \multirow{2}{*}{$\begin{array}{c}\text { Run } \\
\qquad \\
T\end{array}$} & \multicolumn{2}{|c|}{1} & \multicolumn{2}{|c|}{2} \\
\hline & & $c_{p}$ & $\rho$ & $c_{p}$ & $\rho$ \\
\hline Low & $\begin{array}{l}1900 \\
1950 \\
2000 \\
2050 \\
2100 \\
2150 \\
2200\end{array}$ & $\begin{array}{l}31.37 \\
31.48 \\
31.68 \\
31.98 \\
32.39 \\
32.90 \\
33.54\end{array}$ & $\begin{array}{l}53.01 \\
54.65 \\
56.30 \\
57.96 \\
59.63 \\
61.31 \\
63.03\end{array}$ & $\begin{array}{l}30.84 \\
31.28 \\
31.69 \\
32.09 \\
32.48 \\
32.84 \\
33.18\end{array}$ & $\begin{array}{l}53.03 \\
54.66 \\
56.30 \\
57.96 \\
59.63 \\
61.32 \\
63.03\end{array}$ \\
\hline Medium & $\begin{array}{l}2150 \\
2200 \\
2250 \\
2300 \\
2350 \\
2400 \\
2450 \\
2500\end{array}$ & $\begin{array}{l}32.68 \\
33.06 \\
33.47 \\
33.91 \\
34.38 \\
34.90 \\
35.47 \\
36.10\end{array}$ & $\begin{array}{l}61.40 \\
63.10 \\
64.82 \\
66.54 \\
68.28 \\
70.04 \\
71.82 \\
73.62\end{array}$ & $\begin{array}{l}32.24 \\
32,80 \\
33.36 \\
33.92 \\
34.47 \\
35.03 \\
35.58 \\
36.12\end{array}$ & $\begin{array}{l}61.43 \\
63.10 \\
64.80 \\
66.52 \\
68.28 \\
70.05 \\
71.85 \\
73.66\end{array}$ \\
\hline High & $\begin{array}{l}2450 \\
2500 \\
2550 \\
2600 \\
2650 \\
2700 \\
2750 \\
2800 \\
2850 \\
2900\end{array}$ & $\begin{array}{l}34.93 \\
35.46 \\
36.00 \\
36.55 \\
37.13 \\
37.73 \\
38.36 \\
39.03 \\
39.73 \\
40.48\end{array}$ & $\begin{array}{l}71.79 \\
73.57 \\
75.36 \\
77.17 \\
78.98 \\
80.80 \\
82.62 \\
84.45 \\
86.27 \\
88.09\end{array}$ & $\begin{array}{l}35.03 \\
35.55 \\
36.07 \\
36.62 \\
37.19 \\
37.78 \\
38.40 \\
39.05 \\
39.75 \\
40.49\end{array}$ & $\begin{array}{l}71.79 \\
73.58 \\
75.39 \\
77.20 \\
79.02 \\
80.85 \\
82.68 \\
84.51 \\
86.33 \\
88.15\end{array}$ \\
\hline Very high & $\begin{array}{l}2850 \\
2900 \\
2950 \\
3000 \\
3050 \\
3100 \\
3150 \\
3200 \\
3250 \\
3300 \\
3350 \\
3400 \\
3450 \\
3500 \\
3550 \\
3600\end{array}$ & $\begin{array}{l}39.00 \\
39.64 \\
40.31 \\
41.00 \\
41.72 \\
42.47 \\
43.25 \\
44.08 \\
44.96 \\
45.89 \\
46.89 \\
47.97\end{array}$ & $\begin{array}{r}86.61 \\
88.38 \\
90.14 \\
91.88 \\
93.61 \\
95.32 \\
97.00 \\
98.66 \\
100.30 \\
101.91 \\
103.50 \\
105.06\end{array}$ & $\begin{array}{l}38.94 \\
39.62 \\
40.31 \\
41.02 \\
41.76 \\
42.52 \\
43.32 \\
44.15 \\
45.03 \\
45.98 \\
46.99 \\
48.09 \\
49.31 \\
50.67 \\
52.21 \\
54.00\end{array}$ & $\begin{array}{r}86.72 \\
88.48 \\
90.24 \\
91.98 \\
93.70 \\
95.40 \\
97.09 \\
98.75 \\
100.39 \\
102.00 \\
103.59 \\
105.14 \\
106.66 \\
108.14 \\
109.59 \\
111.01\end{array}$ \\
\hline
\end{tabular}

a Temperature in $\mathrm{K}$; heat capacity in $\mathrm{J} \mathrm{mol}^{-1} \mathrm{~K}^{-1}$; electrical resistivity in $10^{-8} \Omega \mathrm{m}$.
TABLE A-2. Experimental results on hemispherical total emittance of tungsten

\begin{tabular}{c|r}
\hline \hline$T$ & \multicolumn{1}{|c}{$\epsilon$} \\
$\mathrm{K}$ & \\
\hline 2333 & 0.323 \\
2336 & .327 \\
2336 & .325 \\
2339 & .328 \\
2668 & .336 \\
2673 & .340 \\
2673 & .339 \\
2678 & .343 \\
3005 & .342 \\
3012 & .346 \\
3013 & .346 \\
3020 & .349 \\
3312 & .347 \\
3323 & .352 \\
3323 & .351 \\
3334 & .356 \\
3407 & .360 \\
34.18 & .355 \\
3418 & .362 \\
3430 & .360 \\
\hline
\end{tabular}

TABLE A-3. Experimental results on normal spectral emittance of tungsten at $\lambda=650 \mathrm{~nm}$

\begin{tabular}{c|c}
\hline \hline$T$ & $\epsilon_{N, \lambda}$ \\
$\mathrm{K}$ & \\
\hline 2076 & 0.380 \\
2111 & .379 \\
2146 & .379 \\
2180 & .379 \\
2214 & .379 \\
2248 & .381 \\
2339 & .378 \\
2393 & .378 \\
2447 & .379 \\
2499 & .379 \\
2551 & .380 \\
2600 & .380 \\
2670 & .379 \\
2739 & .378 \\
2805 & .379 \\
2870 & .379 \\
2933 & .380 \\
\hline
\end{tabular}




\section{References}

[1] Foley, G. M., High-speed optical pyrometer, Rev. Sci. Instr. 41, 827 (1970).

[2] Cezairliyan, A., M. S. Morse, H. A. Berman, and C. W. Beckett, High-speed (subsecond) measurement of heat capacity, electrical resistivity, and thermal radiation properties of molybdenum in the range 1900 to $2800 \mathrm{~K}$, J. Res. Nat. Bur. Stand. (U.S.) 74A (Phys. and Chem.), 65 (1970).

[3] Cezairliyan, A., J. L. McClure, and C. W. Beckett, High-speed (subsecond) measurement of heat capacity, electrical resistivity, and thermal radiation properties of tantalum in the range 1900 to 3200 K, J. Res. Nat. Bur. Stand. (U.S.) 75A (Phys. and Chem.), 1 (1971).

[4] Tietz, T. E. and J. W. Wilson, Behavior and properties of refractory metals (Stanford University Press, California, 1965). p. 28.

[5] International Practical Temperature Scale of 1968, Metrologia 5, 35 (1969)

[6] Hultgren, R., R. L. Orr, P. D. Anderson, and K. K. Kelly, Selected Values of Thermodynamic Properties of Metals and Alloys (John Wiley, New York, 1963).

[7] Schultz, H., "Quenching of vacancies in tungsten," in Lattice Defects in Quenched Metals, R. M. J. Cotterill, M. Doyama, J. J. Jackson and M. Meshi, Eds. (Academic Press, New York, 1965). p. 761

[8] Gripshover, R. J., M. Khoshnevisan, J. S. Zetts, and J. Bass, A study of vacancies in tungsten wires quenched in superfluid helium, Phil. Mag. 22, 757 (1970).

[9] Meakin, J. D., A. Lawley, and R. C. Koo, "Vacancy loops in quenched molybdenum," in Lattice Defects in Quenched Metals, R. M. J. Cotterill, M. Doyama, J. J. Jackson, and M. Meshi, Eds. (Academic Press, New York, 1965). p. 767.

[10] Worthing, A. G., Atomic heats of tungsten and of carbon at incandescent temperatures, Phys. Rev. 12, 199 (1918).

[11] Jaeger, F. M. and E. Rosenbohm, Exact measurement of specific heat of solid substances at high temperatures, III: Pd and W, Koninkl. Ned. Akad. Wetenschap., Proc., Ser. B 33, 457 (1930).

[12] Hoch, M. and H. L. Johnston, A high-temperature drop calorimeter, the heat capacities of tantalum and tungsten between 1000 and 3000 K. J. Chem. Phys. 65, 855 (1961).

[13] Kirillin, V. A., A. E. Sheindlin, V. Ya. Chekhovskoi, and V. A. Petrov, Thermodynamic properties of tungsten, J. Phys. Chem. (USSR) 37, 1212 (1963).

[14] Kraftmakher, Ya. A. and P. G. Strelkov, Energy of formation of and concentration of vacancies in tungsten, Solid State Physics (USSR) 4, 1662 (1963).

[15] Lowenthal, G. C., The specific heat of metals between $1200 \mathrm{~K}$ and $2400 \mathrm{~K}$, Australian J. Phys. 16, 47 (1963).

[16] Hein, R. A. and P. N. Flagella, Enthalpy measurements of $\mathrm{UO}_{2}$ and tungsten to $3260 \mathrm{~K}$. General Electric Report GEMP-578, 1968.
[17] Leibowitz, L., M. G. Chasanov and L. W. Mishler, The enthalpy of solid tungsten from $2800 \mathrm{~K}$ to its melting point, Trans. Met. Soc. AIME 245, 981 (1969).

[18] West, E. D. and S. Ishihara, Enthalpy of tungsten, private communication.

[19] Forsythe, W. E. and A. G. Worthing, The properties of tungsten and the characteristics of tungsten lamps, Astrophys. J. 61, 146 (1925).

[20] Jones, H. A., A temperature scale for tungsten, Phys. Rev. 28, 202 (1926).

[21] Osborn, R. H., Thermal conductivities of tungsten and molybdenum at incandescent temperatures, J. Opt. Soc. Am. 31, 428 (1941).

[22] Platunov, E. S. and V. B. Fedorov, Use of photographic pyrometry in thermal studies, High Temperature 2, 568 (1964).

[23] Neimark, B. E. and L. K. Voronin, Thermal conductivity, specific electrical resistivity, and total emissivity of refractory metals at high temperatures, High Temperature 6, 999 (1968).

[24] Tye, R. P., Preliminary measurements on the thermal and electrical conductivities of molybdenum, niobium, tantalum, and tungsten, J. Less-Common Metals 3, 13 (1961).

[25] Allen, R. D., L. F. Glasier, and P. L. Jordan, Spectral emissivity, total emissivity, and thermal conductivity of molybdenum, tantalum, and tungsten above $2300 \mathrm{~K}$, J. Appl. Phys. 31, 1382 (1960).

[26] Rudkin, R. L., W. J. Parker, and R. J. Jenkins, "Measurement of the thermal properties of metals at elevated temperatures," in Temperature Its Measurement and Control in Science and Industry, C. M. Herzfeld, Ed., Vol. III, part 2, p. 523, (Reinhold, New York, 1962).

[27] Worthing, A. G., The true temperature scale of tungsten and its emissive power at incandescant temperatures, Phys. Rev. 10,377 (1917).

[28] DeVos, J. C., A new determination of the emissivity of tungsten ribbon, Physica 20,690 (1954).

[29] Larrabee, R. D., Spectral emissivity of tungsten, J. Opt. Soc. Am. 49,619 (1959).

[30] Latyev, L. N., V. Ya. Chekhovskoi, and E. N. Shestakov, Experimental determination of emissive power of tungsten in the visible region of the spectrum in the temperature range 1200 to $2600 \mathrm{~K}$, High Temperature 7, 610 (1969).

[31] White, G. K. and S. B. Woods, Electrical and thermal resistivity of the transition elements at low temperatures, Phil. Trans. Royal Soc. (London) 251, 273 (1959).

[32] Forsythe, W. E. and E. M. Watson, Resistance and radiation of tungsten as a function of temperature, J. Opt. Soc. Am. 24, 114 (1934).

(Paper 75A4-670) 